Premiere Educandum: Jurnal Pendidikan Dasar dan Pembelajaran

Volume 10 (1) 227 - 237 December 2020

ISSN: 2088-5350 (Print) / ISSN: 2528-5173 (Online)

Doi: $10.25273 /$ pe.v10i2.7379

The article is published with Open Access at: http://e-journal.unipma.ac.id/index.php/PE

\title{
Analisis self-regulated learning (SRL) siswa kelas VI sekolah dasar di yogyakarta
}

\author{
Rivan Gestiardi $\bowtie$, Universitas Ahmad Dahlan \\ Ika Maryani, Universitas Ahmad Dahlan
}

\section{ika.maryani@pgsd.uad.ac.id}

\begin{abstract}
SRL is important for grade VI students because it becomes a consideration in the learning and teaching process, especially grade VI students who are faced with challenges at the next school level. This study aims to analyze the independent learning (SRL) of grade VI elementary school students in Yogyakarta. This study uses a quantitative descriptive approach with a survey method that describes a phenomenon in a particular area. The number of samples used was 263 grade VI students from ten elementary schools in Yogyakarta. The instrument used was a SRL questionnaire with a Likert scale of 1-5 with an alternative gradation of strongly agree-strongly disagree. The analysis used is quantitative descriptive analysis (descriptive statistics). The results showed that in general, the SRL ability of grade VI elementary schools in Yogyakarta was in the high category. However, if explained based on the indicators, SRL on cognitive indicators and self-reflection is indeed in the high category, but the performance indicators show the moderate category. Therefore, it needs efforts from teachers, schools, parents, and students to be able to improve performance in learning through learning models, learning media, parent and teacher guidance, and school policies that support the creation of a positive learning climate.
\end{abstract}

Keywords: Elementary school students, Self-regulated learning, Yogyakarta Abstrak: SRL penting dimiliki siswa kelas VI karena menjadi sebuah pertimbangan dalam proses belajar dan megajar terutama siswa kelas VI yang dihadapkan pada tantangan jenjang sekolah selanjutnya. Penelitian ini bertujuan untuk menganalisis self-regulated learning (SRL) siswa kelas VI sekolah dasar di Yogyakarta. Penelitian ini menggunakan pendekatan Deskriptif Kuantatif dengan metode survey yang menggambarkan suatu fenomena pada wilayah tertentu. Jumlah sampel yang digunakan adalah 263 siswa kelas VI dari sepuluh sekolah dasar di Yogyakarta. Instrumen yang digunakan adalah kuesioner SRL dengan skala likert 1-5 dengan gradasi alternatif jawaban sangat setuju-sangat tidak setuju. Analisis yang digunakan adalah analisis deskriptif kuantitatif (statistik deskriptif). Hasil penelitian menujukan bahwa artinya secara umum, kemampuan SRL yang dimiliki kelas VI sekolah dasar di Yogyakarta masuk dalam kategori tinggi. Namun jika dijabarkan berdasarkan indikatornya, SRL pada indicator cognitive dan self-reflection memang berada pada kategori tinggi, namun pada indikator performance menunjukkan kategori sedang. Oleh karena itu, perlu upaya dari guru, sekolah, orang tua, maupun siswa untuk dapat meningkatkan performance dalam belajar melalui penerapan model pembelajaran, media pembelajaran, bimbingan orang tua dan guru, serta kebijakan sekolah yang mendukung terciptanya iklim belajar yang positif.

Kata kunci: Siswa SD, Self-regulated learning, Yogyakarta

Received 29 August 2020; Accepted 18 November 2020; Published 01 December 2020

Citation: Gestiardi, R \& Maryani, I. (2020). Analisis Self-Regulated Learning Siswa kelas VI Sekolah Dasar di Yogayakarta. Premiere Educandum: Jurnal Pendidikan Dasar dan Pembelajaran, 10(2), 227 - 237. Doi.org/10.25273/pe.v10i2.7379

\section{(c) BY-NC-SA}

Copyright (C2020 Premiere Educandum : Jurnal Pendidikan Dasar dan Pembelajaran Published by Universitas PGRI Madiun. This work is licensed under the Creative Commons Attribution-NonCommercialShareAlike 4.0 International License. 


\section{PENDAHULUAN}

Sistem penerapan pendidikan nasional di Indonesia masih memiliki banyak permasalahan mulai dari implementasi kurikulum, mata pelajaran yang didominasi mata pelajaran ekstra, angka putus sekolah yang tinggi hingga tidak sesuai lagi dengan cita-cita nasional (Muhammedi, 2016). Standar Nasional Pendidikan masih sulit tercapai khususnya standar kompetensi lulusan, ketenagaan, sarana dan prasarana (Raharjo, 2013). Terkait pembelajaran di sekolah dasar, masih banyak hambatan seperti banyak siswa yang belum memahami materi yang disampaikan oleh guru. Hal ini disebabkan karena guru belum mampu memaksimalkan potensi diri dalam mengajarkan materi kepada siswa. Siswa kelas VI sekolah dasar merupakan kelas tertinggi dengan dihadapkan berbagai ujian seperti ujian sekolah, ujian praktik hingga ujian masuk jenjang sekolah menengah pertama (SMP), sehingga siswa rentan mengalami kecemasan dan kekhawatiran dalam menghadapi tantangan tersebut. Self-regulated learning (SRL) menjadi aspek penting dalam proses pembelajaran sehingga perlu dimiliki oleh siswa kelas VI agar dapat mengatasi tantangan tersebut (Valle et al., 2008).

SRL merupakan proses individu yang mengatur, memperbaiki diri, hingga mempunyai tujuan yang ingin dicapai atau target. Ketika pencapaian itu terwujud, maka ada proses mengevaluasi pencapaian tersebut, ketika proses maksimal dapat tercapai individu biasanya merasakan kepuasan dalam dirinya (Zimmerman, 2002). Siswa kelas VI yang memiliki SRL tinggi akan mencoba untuk mengatur kegiatan belajar, mengontrol perilaku belajar, memantau secara periodik kemajuan target belajar, mengevaluasi dan mendukung sumber-sumber yang diperlukan dalam menunjang prestasi (Santrock, 2007). Sejumlah penelitian membuktikan bahwa SRL memiliki pengaruh yang signifikan terhadap hasil belajar (Wilson \& Narayan, 2016) serta prestasi akademik (Broadbent \& Poon, 2015; Dent \& Koenka, 2016; Wolters \& Hussain, 2015). Tujuan nya agar siswa kelas VI sekolah dasar tidak mengalami kecemasan dan kekhawatiran ketika dihadapkan oleh berbagai ujian dan tantangan ke jenjang selanjutnya sekolah menengah pertama (SMP) serta mampu mencapai tujuan yang diinginkannya.

SRL ditentukan oleh tiga faktor utama yaitu person, behaviour, dan environment (Davis, Chen, van der Zee, Hauff, \& Houben, 2016; Wong et al., 2019). Dalam pembentukan terjadinya SRL ada tiga fase perputaran dalam SRL yaitu pemikiran dan perencanaan (forethought and planning), pemantauan kinerja (performance monitoring), dan refleksi terhadap kinerja (reflections on performance) (Long \& Aleven, 2017; Zimmerman, 1989). SRL didefiniskan sebagai usaha yang dilakukan dengan sengaja terencana, yang bersifat siklus dimana pikiran, perasaan, dan tindakan dikelola untuk mencapai tujuan yang ingin dicapai khususnya dalam meningkatkan hasil belajar (Long \& Aleven, 2017). Penelitian ini bertujuan untuk menganalisis SRL siswa kelas VI sekolah dasar di Yogyakarta. Impilkasi dari hasil penelitian ini diharapkan dapat menambah wawasan ilmu pengetahuan tentang SRL serta diharapkan guru mampu menyadari dan menerapkan SRL kepada siswa khususnya siswa kelas VI sekolah dasar.

\section{METODE}

\section{Jenis Penelitian}

Penelitian ini menggunakan penelitian deskriptif kuantitatif yakni menggambarkan fenomena untuk mengetahui sesuatu hal yang terjadi (Gall, Gall, \& Borg, 2014). Desain penelitian ini juga masuk dalam format desain penelitian ex-post facto. Ex-post facto merupakan metode yang banyak dipakai dalam situasi permasalahan pendidikan. 


\section{Populasi dan Sampel Penelitian}

Populasi penelitian yakni siswa kelas VI sekolah dasar di kota Yogyakarta yang berjumlah 7760 siswa (Data peserta UN tahun 2018/2019). Jenis probability sampling yang digunakan dalam pengambilan sampel pada penelitian ini adalah sample random sampling dikatakan simple (sederhana) karena pengambilan anggota sampel dari populasi dilakukan secara acak tanpa memperhatikan strata yang ada dalam populasi itu (Sugiyono, 2014).

Penelitian ini menggunakan teknik pengumpulan data berupa kuesioner online yang dilakukan pada bulan Juni-Juli, 2020 melalui google form yang dibagikan secara random ke berbagai sekolah dasar di Yogyakarta khususnya kelas VI sekolah dasar, sampai batas waktu yang ditentukan. Berdasarkan hasil kueisoner responden tersebut terdapat 311 siswa kemudian direduksi. Reduksi data menurut (Miles \& Huberman, 1992) diartikan sebagai proses pemilihan, pemusatan perhatian pada penyederhanaan, pengabstrakan, dan tranformasi data "kasar" yang muncul dari catatan-catatan tertulis di lapangan. Hasil nya ialah didapatkan data bersih berjumlah 263 siswa dari 10 sekolah dasar di Yogyakarta, sisanya data kotor tidak diikutkan dalam proses penelitian ini.

Pengambilan sampel dalam penelitian ini, peneliti menggunakan Tabel menurut teori Cohen Manion dan Marrison diketahui bahwa Tabel teori tersebut, mempunyai kelebihan yakni penentuan populasi yang diprediksi dalam pengambilan sampelnya hingga 1 juta populasi, dapat merinci taraf keyakinan penelitian dari 90\%, 95\% dan 99\%, hingga merinci interval keyakinan penelitian (alpha) yaitu dari 0,1, 0,005 dan 0,01. Oleh karena total populasi siswa kelas VI sekolah dasar di kota Yogyakarta yang berjumlah 7760 siswa (Data peserta UN tahun 2018/2019), maka sampel penelitian yang diambil berjumlah 263 siswa dengan beberapa pertimbangan, yaitu perkiraan populasi sebesar 7760, taraf keyakinan penelitian sebesar 90\% dengan menggunakan alpha sebesar 0,1. Distribusi sampel dapat dilihat pada TABEL 1.

TABEL 1. Distribusi sampel

\begin{tabular}{|c|c|c|c|c|}
\hline No & Nama Sekolah & Kelas & Umur & Jumlah Siswa \\
\hline 1. & SD Negeri Bhayangkara & VI & $12 \mathrm{Th}$ & 42 Siswa \\
\hline 2. & SD Muhammadiyah KlecoTerpadu & VI & $12 \mathrm{Th}$ & 50 Siswa \\
\hline 3. & SD Muhammadiyah Sagan & VI & $12 \mathrm{Th}$ & 50 Siswa \\
\hline 4. & SD MuhammadiyahDanunegaran & VI & $12 \mathrm{Th}$ & 9 Siswa \\
\hline 5. & SD Negeri Bangirejo & VI & $12 \mathrm{Th}$ & 23 Siswa \\
\hline 6. & SD Muhammadiyah Ngupasan & VI & $12 \mathrm{Th}$ & 17 Siswa \\
\hline 7. & MI Nurul Ummah & VI & $12 \mathrm{Th}$ & 19 Siswa \\
\hline 8. & SD Al-amin sinar putih & VI & $12 \mathrm{Th}$ & 8 Siswa \\
\hline 9. & SD Negeri Baciro & VI & $12 \mathrm{Th}$ & 23 Siswa \\
\hline 10. & SD Negeri Gedongtengen & VI & $12 \mathrm{Th}$ & 22 Siswa \\
\hline \multicolumn{2}{|r|}{ Jumlah } & & & 263 Siswa \\
\hline
\end{tabular}

\section{Instrumen Penelitian}

Instrumen utama yang digunakan dalam penelitian ini adalah kuesioner SRL dengan skala likert 1-5. Indikator SRL dalam penelitian ini adalah cognitive, performance dan selfreflection (Boekaerts, Zeidner, \& Pintrich, 2000). Kisi-kisi kuisioner SRL dapat dilihat pada TABEL 2.

\section{Analisis Data}

Data yang dihasilkan dalam penelitian ini berupa data kuantitatif. Penyajian data deskriptif kuantitatif yang diperoleh dari hasil kuesioner yang dibagikan secara online, kemudian data dianalisis dengan menggunakan metode deskriptif statistik. Hasil 
penelitian kemudian disajikan dalam bentuk gambar dan tabel. Kriteria dalam mengkategorisasi kemampuan SRL dihitung melalui distribusi kurva normal. Kriteria SRL dan aspeknya dapat dilihat pada TABEL 3.

TABEL 2. Kisi-kisi kuisioner SRL

\begin{tabular}{|c|c|c|c|c|}
\hline \multirow[t]{2}{*}{ Dimensi } & \multirow[t]{2}{*}{ Indikator } & \multicolumn{2}{|c|}{ Nomor Pernyataan } & \multirow[t]{2}{*}{ Jumlah } \\
\hline & & $\begin{array}{c}\text { Favorable } \\
(+)\end{array}$ & $\begin{array}{c}\text { Unfavorable } \\
(-)\end{array}$ & \\
\hline \multirow[t]{6}{*}{ Cognitive } & Self Analysis Task & 2,3 & 7,8 & 4 \\
\hline & Self motivational belief & 28 & 31 & 2 \\
\hline & Harapan akan hasil & 27 & 29 & 2 \\
\hline & Pendekatan internal & 30 & 15 & 2 \\
\hline & Orientasi terhadap tujuan & 25 & 6 & 2 \\
\hline & & \multicolumn{2}{|c|}{ Jumlah item dimensi kognitif } & 12 \\
\hline \multirow[t]{7}{*}{ Performance } & Imajinary & 14 & 9 & 2 \\
\hline & Self control & 32 & 24 & 2 \\
\hline & Attention focusing & 16,20 & 22,5 & 4 \\
\hline & Task strategy & 33 & 34 & 2 \\
\hline & Self observation & 12 & 23 & 2 \\
\hline & Self eksperimentation & 17 & 21 & 2 \\
\hline & \multicolumn{3}{|c|}{ Jumlah item dimensi performace } & 14 \\
\hline \multirow[t]{4}{*}{ Self Reflection } & Selfjudgement & 1,18 & 19,13 & 4 \\
\hline & Self reaction & 4,10 & 11,26 & 4 \\
\hline & \multicolumn{3}{|c|}{ Jumlah item dimensi self reflection } & 8 \\
\hline & \multicolumn{3}{|c|}{ Total Item Skala Self Regulated Learning (SRL) } & 34 \\
\hline
\end{tabular}

TABEL 3. Kategori SRL dan aspeknya

\begin{tabular}{lcccc}
\hline \multicolumn{1}{c}{ Kategori } & Interval SRL & $\begin{array}{c}\text { Interval SRL } \\
\text { aspek cognitive }\end{array}$ & $\begin{array}{c}\text { Interval SRL aspek } \\
\text { Performance }\end{array}$ & $\begin{array}{c}\text { Interval SRL } \\
\text { aspek Self- } \\
\text { Reflection }\end{array}$ \\
\hline Sangat Rendah & $\mathrm{X} \leq 68$ & $\mathrm{X} \leq 24$ & $\mathrm{X} \leq 28$ & $\mathrm{X} \leq 16$ \\
Rendah & $68<\mathrm{X} \leq 90,65$ & $24<\mathrm{X} \leq 32$ & $28<\mathrm{X} \leq 37,35$ & $16<\mathrm{X} \leq 21,35$ \\
Sedang & $90,65<\mathrm{X} \leq 113,35$ & $32<\mathrm{X} \leq 40$ & $37,35<\mathrm{X} \leq 46,65$ & $21,35<\mathrm{X} \leq 26,65$ \\
Tinggi & $113,35<\mathrm{X} \leq 136$ & $40<\mathrm{X} \leq 48$ & $46,65<\mathrm{X} \leq 55,95$ & $26,65<\mathrm{X} \leq 31,95$ \\
Sangat Tinggi & $136<\mathrm{X}$ & $48<\mathrm{X}$ & $55,95<\mathrm{X}$ & $31,95<\mathrm{X}$ \\
\hline
\end{tabular}

\section{HASIL PENELITIAN}

Berdasarkan hasil kuesioner yang telah terkumpul dari 263 responden siswa kelas VI sekolah dasar didapatkan data berupa angka yang dapat ditabulasi dan disajikan dalam bentuk gambar dan tabel. Pada pengolahan persentase didapatkan hasil persentase dari frekuensi siswa tiap kategori yaitu sangat rendah, rendah, sedang, tinggi dan sangat tinggi dalam menganalisis kemampuan SRL siswa kelas VI sekolah dasar. Persentase tersebut dikategorikan sebagai kemampuan SRL siswa berdasarkan indikatornya. Frekuensi yang paling tinggi pada setiap kategori merupakan cerminan kategori tersebut.

Berdasarkan statistic deskriptif, diperoleh mean sebesar 113,90 dengan nilai maksimum 170 dan nilai minimum 74, dengan standar deviasi sebesar 10,729. Selanjutnya yakni mengkategorikan kemampuan SRL berdasarkan kuesioner yang telah diisi oleh siswa kelas VI sekolah dasar di Yogyakarta. Adapun presentase SRL siswa kelas VI sekolah di Yogyakarta diuraikan pada GAMBAR 1. 


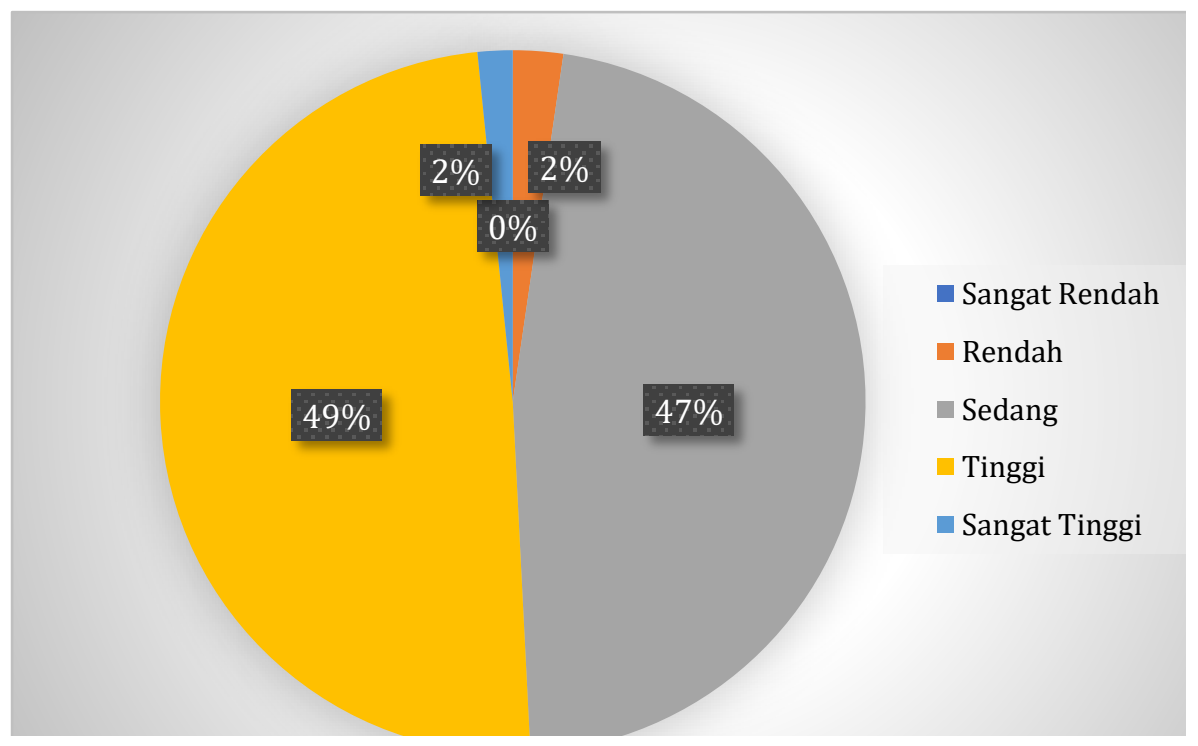

GAMBAR 1. Presentase kategori SRL siswa kelas VI di Yogyakarta

Berdasarkan GAMBAR 1. dapat diketahui bahwa hasil dari frekuensi jawaban kuesioner yang terdiri dari 5 kategori penilaian terdapat presentase kemampuan SRL berdasarkan jawaban kuesioner yakni, terdapat $2 \%$ sangat tinggi, $49 \%$ siswa yang mempunyai kemampuan SRL tinggi, $47 \%$ sedang, $2 \%$ rendah, dan $0 \%$ sangat rendah. Data tersebut menggambarkan dominasi SRL sedang-tinggi pada siswa kelas VI SD di Yogyakarta. Selanjutnya, melakukan pengelompokan kemampuan SRL siswa berdasarkan indikator. Adapun pengelompokan kemampuan SRL berdasarkan indikator, dapat dilihat pada Gambar 2.

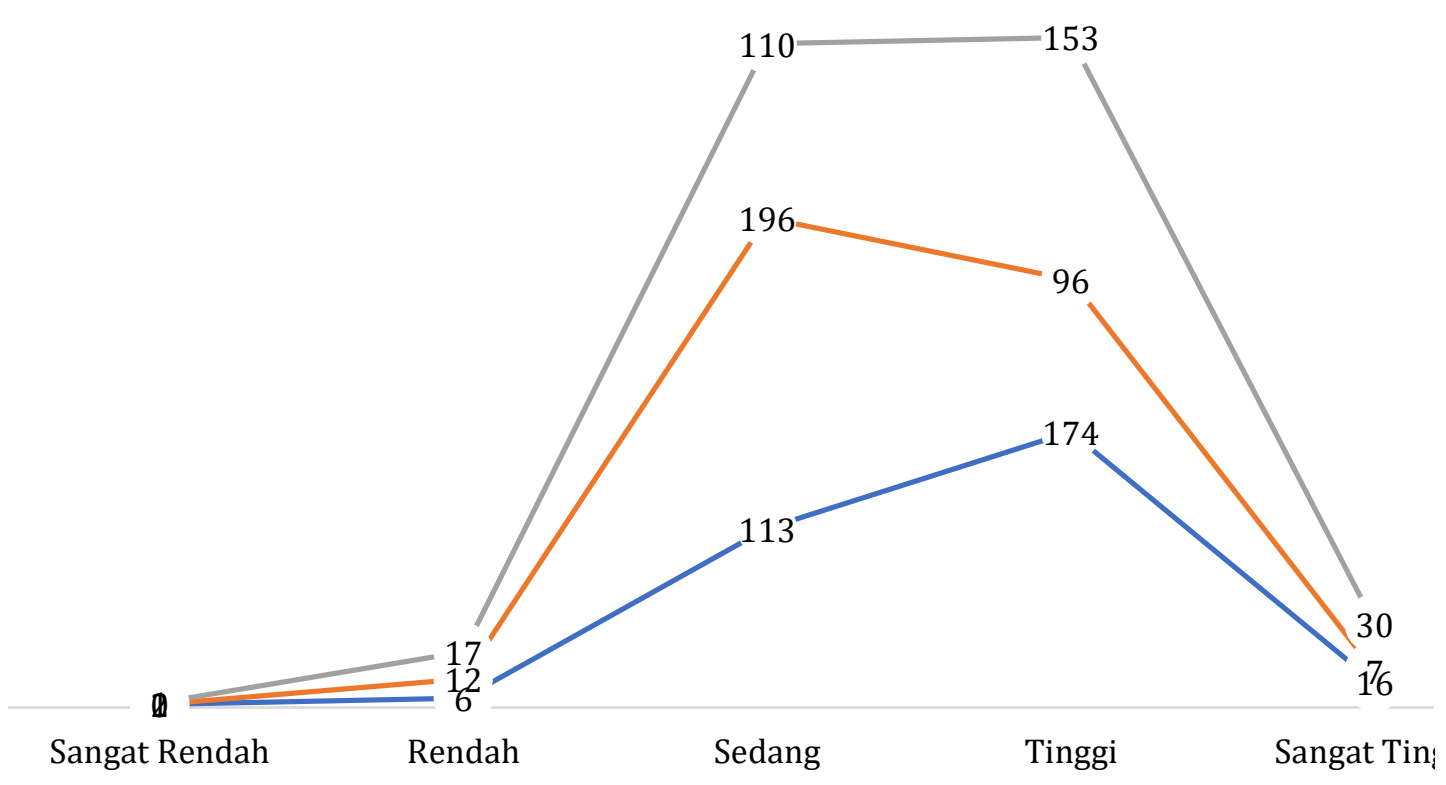

GAMBAR 2. Frekuensi Kemampuan SRL Berdasarkan Indikator Siswa kelas VI di Yogyakarta

Berdasarkan GAMBAR 2, setiap indikator SRL siswa kelas VI sekolah dasar di Yogyakarta tidak semua siswa mempunyai kemampuan SRL yang tinggi. Hasil analisis kemampuan SRL siswa kelas VI sekolah dasar di Yogyakarta menunjukan bahwa pada indikator kognitif dan self-reflection banyak siswa yang memiliki SRL tinggi dengan 
masing-masing berjumlah 174 siswa dan 153 siswa. Namun pada indikator performance siswa cenderung memiliki SRL sedang berjumlah 113 siswa. Lebih lanjut diperlukan beberapa strategi untuk meningkatkan SRL khususnya pada siswa yang memiliki kemampuan rendah pada setiap aspek indikator. Perbandingan SRL tiap sekolah berdasarkan indikator di Yogyakarta dapat dilihat pada TABEL 4.

TABEL 4. Rekap kemampuan self-regulated learning antar sekolah berdasarkan indikator

\begin{tabular}{|c|c|c|c|c|c|c|c|c|c|c|c|c|c|c|c|c|}
\hline \multirow[t]{2}{*}{ No } & \multirow[t]{2}{*}{ Nama Sekolah } & \multicolumn{5}{|c|}{ Cognitive (\%) } & \multicolumn{5}{|c|}{ Performance (\%) } & \multicolumn{5}{|c|}{ Self-Reflection (\%) } \\
\hline & & SR & $\mathbf{R}$ & $\mathbf{S}$ & $T$ & ST & SR & $\mathbf{R}$ & $\mathbf{S}$ & $\mathrm{T}$ & ST & SR & $\mathbf{R}$ & $\mathbf{S}$ & $T$ & ST \\
\hline 1 & $\begin{array}{l}\text { SD Negeri } \\
\text { Bhayangkara }\end{array}$ & 0 & 2 & 20 & 68 & 10 & 0 & 2 & 64 & 30 & 4 & 0 & 0 & 20 & 58 & 22 \\
\hline 2 & $\begin{array}{l}\text { SD Muhammadiyah } \\
\text { Kleco }\end{array}$ & 1 & 0 & 35 & 58 & 6 & 0 & 4 & 65 & 31 & 0 & 1 & 3 & 30 & 53 & 13 \\
\hline 3 & $\begin{array}{l}\text { SD Muhammadiyah } \\
\text { Sagan }\end{array}$ & 0 & 0 & 48 & 49 & 3 & 0 & 1 & 65 & 32 & 1 & 0 & 1 & 43 & 51 & 5 \\
\hline 4 & $\begin{array}{l}\text { SD Muhammadiyah } \\
\text { Danunegaran }\end{array}$ & 0 & 0 & 55 & 33 & 11 & 0 & 0 & 22 & 68 & 11 & 0 & 0 & 22 & 78 & 0 \\
\hline 5 & SD Negeri Bangirejo & 0 & 0 & 13 & 83 & 4 & 0 & 0 & 13 & 61 & 26 & 0 & 0 & 48 & 43 & 9 \\
\hline 6 & $\begin{array}{l}\text { SD Muhammadiyah } \\
\text { Ngupasan } 2\end{array}$ & 0 & 6 & 29 & 65 & 0 & 0 & 18 & 65 & 18 & 0 & 0 & 6 & 41 & 41 & 12 \\
\hline 7 & MI Nurul Ummah & 5 & 5 & 63 & 26 & 0 & 0 & 10 & 58 & 31 & 0 & 0 & 16 & 37 & 42 & 5 \\
\hline 8 & $\begin{array}{l}\text { SD AL-Amin Sinar } \\
\text { Putih }\end{array}$ & 0 & 0 & 37 & 50 & 12 & 0 & 12 & 62 & 12 & 12 & 0 & 25 & 25 & 37 & 12 \\
\hline 9 & $\begin{array}{l}\text { SD Negeri } \\
\text { Gedongtengn }\end{array}$ & 0 & 4 & 41 & 50 & 4 & 0 & 4 & 64 & 27 & 4 & 0 & 14 & 23 & 45 & 18 \\
\hline 10 & SD Negeri Baciro & 0 & 9 & 35 & 52 & 4 & 0 & 4 & 52 & 35 & 9 & 0 & 9 & 26 & 52 & 13 \\
\hline
\end{tabular}

TABEL 4 menunjukan bahwa pada hasil rekap SRL antar sekolah berdasarkan indikator cognitive menunjukan sekolah yang mempunyai kategori tinggi dengan presentase terbesar adalah SD Negeri Bangirejo dengan total sebesar 83\% dari jumlah total siswa dan sekolah yang mempunyai ketegori rendah terbesar ialah SD Negeri Baciro sebesar 9\% jumlah total siswa. Pada indikator performance sekolah yang mempunyai kategori tinggi dengan presentase terbesar adalah SD Muhammadiyah Danunegaran dengan total sebesar $68 \%$ dari jumlah total siswa, sedangkan sekolah yang mempunyai kategori rendah dengan presentase terbesar ialah SD Muhammadiyah Ngupasan 2 sebesar $18 \%$ dari jumlah total siswa. Pada indikator self-reflection sekolah yang mempunyai kategori tinggi dengan presentase terbesar adalah SD Muhammadiyah Danunegaran dengan total sebesar 78\% dari jumlah total siswa, dan sekolah yang mempunyai kategori rendah terbesar ialah SD Al-Amin Sinar Putih sebesar 37\% dari jumlah total siswa. Selanjutnya berdasarkan skor SRL secara umum, kategori SRL tiap sekolah ditunjukkan dalam TABEL 5.

TABEL 5. Rekap presentase kemampuan SRL tiap sekolah

\begin{tabular}{clccccc}
\hline \multirow{2}{*}{ No. Nama SD } & \multicolumn{5}{c}{ Presentase Kemampuan SRL (\%) } \\
\cline { 3 - 6 } & & SR & R & S & T & ST \\
\hline 1. & SD Negeri Bhayangkara & 0 & 0 & 28 & 70 & 2 \\
2. & SD Muhammadiyah Kleco & 0 & 1 & 45 & 53 & 0 \\
3. & SD Muhammadiyah Sagan & 0 & 1 & 51 & 46 & 1 \\
4. & SD Muhammadiyah Danunegaran & 0 & 0 & 55 & 44 & 0 \\
5. & SD Negeri Bangirejo & 1 & 46 & 51 & 1 & 0 \\
6. & SD Muhammadiyah Ngupasan 2 & 0 & 6 & 59 & 35 & 0 \\
7 & MI Nurul Ummah & 0 & 5 & 53 & 42 & 0 \\
8. & SD AL-Amin Sinar Putih & 0 & 0 & 62 & 37 & 0 \\
9. & SD Negeri Gedongtengn & 0 & 0 & 50 & 50 & 0 \\
10 & SD Negeri Baciro & 0 & 9 & 39 & 43 & 9 \\
\hline
\end{tabular}

Ket: SR = Sangat Rendah $\mathrm{R}=$ Rendah $\mathrm{S}=$ Sedang $\mathrm{T}=$ Tinggi $\mathrm{ST}=$ Sangat Tinggi 
Selanjutnya dari TABEL 5. Tentang hasil rekap presentase kemampuan SRL data akan disajikan dalam bentuk line chart. Line chart dapat dilihat pada GAMBAR 3.

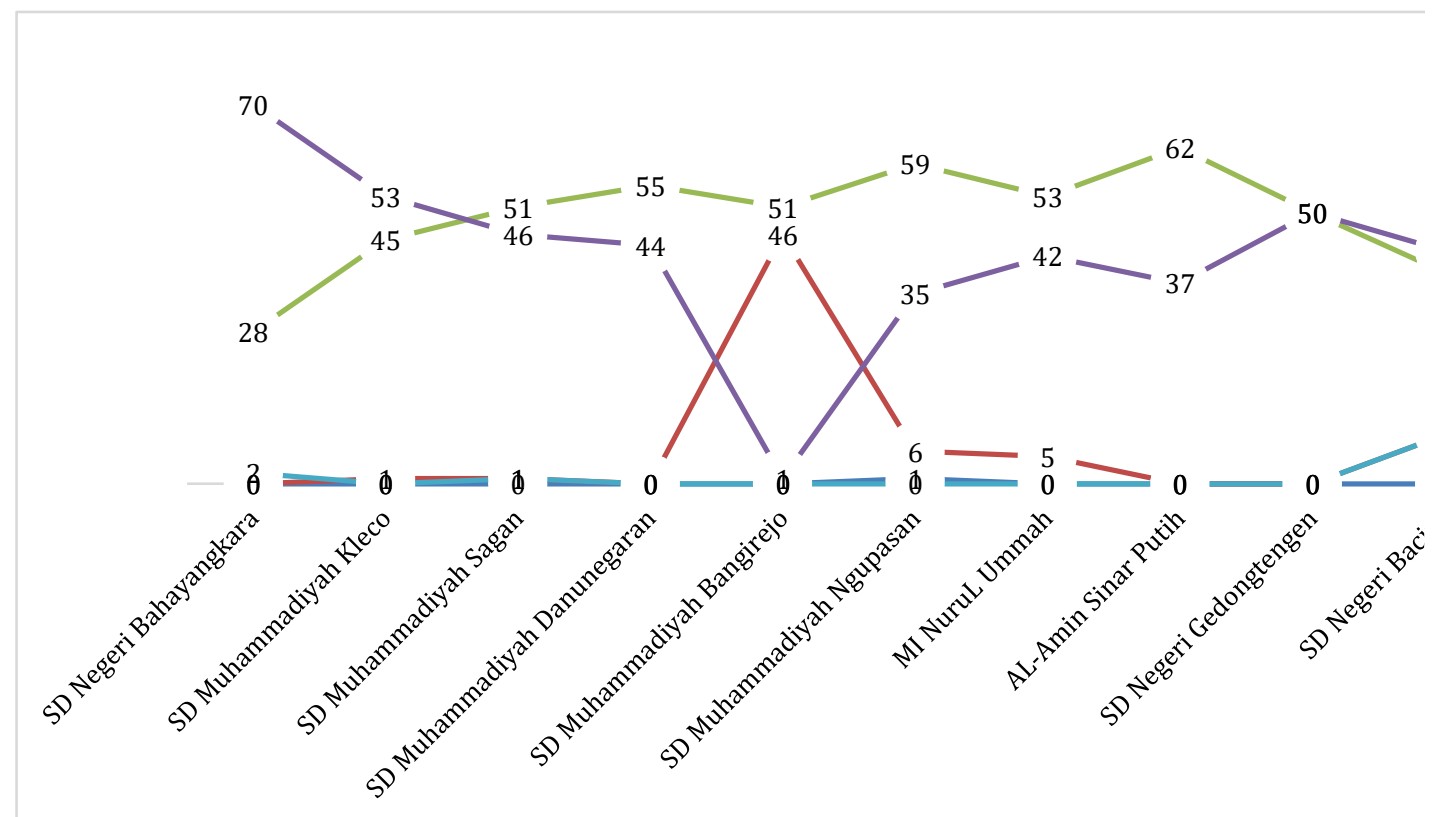

GAMBAR 2. Presentase kemampuan SRL Tiap Sekolah

Berdasarkan TABEL 4 dan GAMBAR 3, dapat diketahui bahwa hasil rekap presentase kemampuan SRL tiap sekolah menunjukan sekolah yang mempunyai kategori tinggi dengan presentase terbesar adalah SD Negeri Bhayangkara dengan total sebesar $70 \%$ dari total seluruh siswa. Sedangkan sekolah yang mempunyai kategori rendah dengan presentase terbesar ialah SD Negeri Bangirejo dengan total sebesar $46 \%$ dari jumlah total seluruh siswa.

\section{PEMBAHASAN}

SRL merupakan usaha yang dilakukan dengan sengaja, terencana yang bersifat siklus dimana pikiran, perasaan dan tindakan dikelola untuk mencapai tujuan khususnya dalam belajar/akademik (Zimmerman, 1989). Dengan demikian, maka penting untuk individu dalam meyakini dan merencakan tindakan emosinya untuk menyelesaikan tugas tertentu dalam belajar. SRL terdiri dari tiga tahapan fase perputaran yakni kognitif, tindakan dan self-reflection. Menurut Sulisworo et al (2020) dan Zumbrunn, Tadlock, and Roberts (2011), ada tiga fase perputaran dalam SRL yaitu pemikiran dan perencanaan (forethought and planning), pemantauan kinerja (perfomance monitoring), dan refleksi terhadap kinerja (reflections on performance).

Indikator $S R L$ secara garis besarnya meliputi fase kognitif, fase performance dan selfreflection. Ketiga tahapan fase tersebut yang akan digunakan dalam penelitian ini untuk menganalisis SRL kelas VI sekolah dasar di Yogyakarta. Pendapat tersebut diperjelas oleh Boekaerts et al (2000) bahwa tahapan yang menjadi siklus terjadinya $S R L$ yakni tahapan kognitif yang terdiri task analysis yakni membuat tujuan yang spesifik dan membuat strategi perencanaan untuk menguasai atau mengoptimalkan tindakan/performa, selfmotivational belief terdiri dari self-efficacy (keyakinan akan kemampuan diri), outcome expectation (harapan akan hasil yang diperoleh), intrinsic interest/ value strategy (ketertarikan dari dalam diri), goal orientation (orientasi tujuan). Tahapan tindakan/performance yang terdiri dari, self-control terdiri dari self-intruction (baik tampak maupun tidak guna menggambarkan proses penyelesaian tugas), 
imagery/membayangkan, attention focusing (guna meningkatkan konsentrasi), dan task strategy (guna mereduksi tugas menjadi bagian-bagian penting dan menata menjadi bagian-bagian yang berarti), self-observation digunakan untuk mentracking aspek khusus performance yang dilakukan dengan menggunakan self-experimentation. Self-reflection yang terdiri dari self-judgment yakni mengevaluasi performa yang telah dilakukan dan hasil yang diinginkan, self-reaction yakni reaksi kognitif dan emosi dari hasil evaluasi performance dan hasil dalam meraih tujuan, reaksi ini akan mempengaruhi pada siklus lainnya.

Menurut Agholor (2019) dan Schunk and DiBenedetto (2020) perilaku manusia dibahas dalam kerangka determinisme timbal balik (triadic reciprocality determinism) antara perilaku, lingkungan dan pribadi, terdapat 3 hal yang mempengaruhi seseorang sehingga melakukan/menyadari $S R L$ yaitu faktor pribadi dijelaskan bahwa proses pribadi untuk mengatur strategi belajar dan lingkungan belajar, dijelaskan juga bahwa pada pribadi seorang terdapat suatu keyakinan tentang kemampuan untuk mengatur dan menyelesaikan suatu tugas yang diperlukan untuk mencapai tujuan yang diingiinkannya.

Faktor pribadi-lingkungan dijelaskan pada siswa yang mengalami kesulitan belajar akan terjadi interaksi antara pribadi dengan faktor lingkungan. Siswa yang memiliki kesulitan belajar akan mengalami rendah diri. Di dalam lingkungan sosial akan bergabung dengan yang sama-sama memiliki kesulitan belajar sehingga apabila mereka diberi tugas atau tanggungjawab maka tingkat SRLnya juga akan tergolong rendah. Hal ini tidak akan terjadi jika siswa memiliki SRL, karena SRL menjadi variabel penting bagi siswa untuk mencapai kesuksesan akademik yang mereka jalani di sekolah. SRL memiliki pengaruh signifikan terhadap performa akademik (Wilson \& Narayan, 2016) juga prestasi akademik (Broadbent \& Poon, 2015; Dent \& Koenka, 2016; Wolters \& Hussain, 2015), yang berarti selain performa akademik yang baik, tingkat SRL siswa yang tinggi akan mendorong siswa mencapai prestasi akademik yang maksimal sesuai dengan harapan setiap siswa.

Pada GAMBAR 1, Berdasarkan presentase SRL hal itu tak lepas dari strategi, dalam menentukan jawaban/pilihan menurut Zumbrunn et al (2011) menyebutkan beberapa strategi untuk menjadi SRL yaitu a) perencanaan merupakan proses perencanaan hampir sama dengan penetapan tujuan, perencanaan dapat membantu siswa untuk mengatur dirinya sebelum memilih atau menentukan jawaban; b) penetapan tujuan yakni siswa tahu apa yang ingin mereka capai setelah membaca atau belajar; c) motivasi diri yakni siswa memiliki self-efficiacy yang tinggi dalam menyelesaikan tugas tepat waktu; d) kontrol atensi yakni berusaha memfokuskan perhatian mereka terhadap pelajaran yang sedang berlangsung; e) penggunaan strategi belajar yang fleksibel artinya memiliki stragei yang berbeda tergantung tujuan yang diinginkannya; f) monitor diri siswa akan mengubah gaya belajar atau memodifikasi; g) mencari bantuan yakni siswa menyadari mereka membutuhkan bantuan orang lain; h) evaluasi diri yakni menyadari dan melihat apakah mereka telah memenuhi tujuan yang diinginkan atau belum.

Penelitian ini menunjukan bahwa strategi dalam membentuk SRL pada siswa kelas VI sekolah dasar di Yogyakarta sudah terlihat saling melengkapi dan telah memenuhi kriteria dalam pembentukan SRL dalam hal ini dikatakan bahwa siswa kelas VI sekolah dasar di Yogyakarta masuk dalam kategori sangat baik. Hasil tersebut sejalan dengan penelitian yang dilakukan oleh Zimmerman and Martinez-Pons (1990) bahwa siswa yang berprestasi tinggi menggunakan 10-13 dari 14 strategi, dan siswa yang berprestasi rendah juga mempergunakan strategi SRL tetapi rendah.

Hasil analisis pada GAMBAR 2, ditinjau dari frekuensi kemampuan SRL berdasarkan indikator SRL diketahui bahwa faktor-faktor yang mempengaruhi tingkat perbedaan kemampuan masing-masing indikator SRL tersebut bersifat relatif, sehingga hal yang mempengaruhi tingkat kemampuan masing-masing tahapan indikator cenderung dari luar diri individu atau eksternal. Menurut Zumbrunn et al (2011) menyebutkan salah satu strategi agar dapat mengimbangi tingkat perbedaan kemampuan masing-masing siswa yakni dengan cara pencarian bantuan (help-seeking) dimana siswa yang mandiri tidak 
mencoba untuk menyelesaikan tugasnya sendiri, melainkan mencari bantuan orang lain dalam menyelesaikan tugasnya, hal ini menjadi nilai positif apabila mampu diterapkan diseluruh aspek dengan tujuan membuat diri mereka lebih otonom dan mampu belajar dari sebelumnya. Hal tersebut menunjukan bahwa manusia adalah makhluk sosial, sehingga manusia tidak dapat hidup tanpa bantuan orang lain. Hal tersebut memungkinkan pada hasil frekuensi kemampuan SRL berdasarkan indikator SRL secara keseluruhan tergolong dalam kategori baik.

Hasil analisis pada TABEL 4, tentang rekap kemampuan SRL antar sekolah berdasarkan indikator, menunjukan bahwa pada indikator kognitif sekolah yang mempunyai besaran kemampuan tertinggi yakni SD Negeri Bangirejo dengan dengan presentase $83 \%$ dari jumlah siswa. Indikator kognitif SRL sejalan dengan taksonomi bloom pada aspek kognitif yakni berupa menganalisis tugas-tugas (C4), menetapkan tujuan (C3), menetapkan strategi belajar (C4) dan menyesuaikan strategi belajar (C4) artinya SD Negeri Bangirejo sudah menerapkan indikator kognitif dalam proses pembelajaran kegiatannya. Aspek kognitif pada SRL dapat dihubungkan dengan kepuasan kerja guru untuk mengurangi kelelahan emosional siswa. Hal ini tidak dipengaruhi oleh jenis kelamin maupun jalur sekolah (Mattern \& Bauer, 2014). Oleh karena itu, guru memiliki peran penting dalam memberdayakan SRL siswa kelas VI untuk menghadapi berbagai tantangan di level kelasnya. Pada indikator performance SD Muhammadiyah Danunegaran menjadi sekolah dengan besaran kemampuan tinggi terbesar sebesar $68 \%$ dari keseluruhan jumlah siswa. Artinya SD Muhammdiyah Danunegaran sudah berhasil menerapkan indikator performance yang dapat memunculkan perilaku-perilaku yang positif menunjang prestasi serta indikator performance menyebabkan kinerja memiliki nilai akademis yang lebih tinggi. Intervensi pembelajaran yang melatih kombinasi strategi metakognitif dan kognitif dapat meningkatkan performance siswa (Cazan, 2013). Pada indikator self-reflection sekolah dengan besaran kemampuan tinggi terbesar yakni SD Muhammadiyah Danunegaran dengan $78 \%$ siswa dari jumlah siswa yang mempunyai kemampuan tinggi. Hasil ini juga menunjukan SD Muhammdiyah Danunegaran sudah menerapkan indikator self-reflection dengan cara menentukan sejauh mana strategi belajar, mengidentifikasi alternatif yang afektif dalam situasi belajar dimasa depan. Selfreflection diprediksi dapat meningkatkan pemikiran positif siswa, motivasi belajar dan self-regulation (Wang, Chen, Lin, \& Hong, 2017).

Berdasarkan hasil analisis pada TABEL 4, TABEL 5 dan GAMBAR 3. Menunjukan bahwa sekolah yang mempergunakan strategi SRL menunjukan hasil yang lebih bagus dibanding sekolah yang tidak menerapkan SRL di dalam proses pembelajarannya. Ketika sekolah mampu mengembangkan dan menerapkan SRL, maka pencapaian tujuan yang telah ditetapkan dapat tercapai, dengan SRL para siswa menjadi mahir dalam pembelajaran mandiri dapat meningkatkan hasil belajar (Tosi, Locke, \& Latham, 1991). Jadi SRL dapat mempengaruhi hasil belajar. Pada tataran praktik pembelajaran dan kebijakan, perlu diterapkan berbagai strategi yang mendorong tumbuhnya SRL (Bala, Sulisworo, \& Maryani, 2020). Pada perbandingan SRL antar sekolah memiliki tujuan yang positif yakni peneliti dapat mengetahui besaran kemampuan tertinggi dan terkecil artinya data tersebut menjadi sebuah acuan agar setiap sekolah dapat selalu meningkatkan kemampuan SRL siswanya melalui strategi SRL dan perencanaan terprogram dalam mengembangkan pengajaran dan pembelajaran kepada siswa.

\section{SIMPULAN}

Pada hasil seluruh pengkategorisasian tersebut tentang analisis SRL ditinjau dari deskripsi data, presentase SRL dan frekuensi kemampuan SRL berdasarkan indikator menunjukan bahwa ketiga analisis tersebut mendapatkan kategori tinggi dalam kemampuan SRL. Hal tersebut dapat ditindaklanjuti dengan mengidentifikasi penyebab masing-masing faktor yang mempengaruhi. Juga, guru perlu mengembangkan strategi baik secara eksplist 
maupun implisit dalam meningkatkan dan mengajarkan SRL kepada siswa. Impilikasi dari hasil penelitian ini adalah guru dan sekolah perlu menjalin kerjasama dalam meningkatkan kemampuan SRL siswanya.

\section{UCAPAN TERIMA KASIH}

Pimpinan Daerah Muhammadiyah Kota Yogyakarta yang telah memfasilitasi proses pengumpulan data dan Universitas Ahmad Ahmad Dahlan sebagai lembaga penelitian.

\section{DAFTAR PUSTAKA}

1. Agholor. (2019). A review of extension self-efficacy: bases, features, goal realisation and implications for extension. South African Journal of Agricultural Extension, 47(2), 140-149.

2. Bala, R., Sulisworo, D., \& Maryani, I. (2020). The analysis of self-regulation learning on elementary schools at the rural area in Indonesia. Universal Journal of Educational Research, 8(2), 395-401. https://doi.org/10.13189/ujer.2020.080209

3. Boekaerts, M., Zeidner, M., \& Pintrich, P. R. (2000). Handbook of Self-Regulation. https://doi.org/10.1016/B978-0-12-109890-2.X5027-6

4. Broadbent, J., \& Poon, W. L. (2015). Self-Regulated Learning Strategies \& Academic Achievement in Online Higher Education Learning Environments: A Systematic Review. Internet and Higher Education, 27, 1-13. https://doi.org/10.1016/j.iheduc.2015.04.007

5. Cazan, A.-M. (2013). Teaching Self Regulated Learning Strategies for Psychology Students. Procedia - Social and Behavioral Sciences, 78, 743-747. https://doi.org/10.1016/j.sbspro.2013.04.387

6. Davis, D., Chen, G., van der Zee, T., Hauff, C., \& Houben, G. J. (2016). Retrieval Practice and Study Planning in MOOCs: Exploring Classroom-Based Self-Regulated Learning Strategies at Scale. Lecture Notes in Computer Science (Including Subseries Lecture Notes in Artificial Intelligence and Lecture Notes in Bioinformatics), 9891 LNCS, 57-71. https://doi.org/10.1007/978-3-319-45153-4_5

7. Dent, A. L., \& Koenka, A. C. (2016). The Relation Between Self-Regulated Learning and Academic Achievement Across Childhood and Adolescence: A Meta-Analysis. Educational Psychology Review, 28(3), 425-474. https://doi.org/10.1007/s10648015-9320-8

8. Gall, M. D., Gall, J., \& Borg, W. (2014). Applying Educational Research: How to Read, Do, and Use Research to Solve Problems of Practice (7th ed.). Pearson.

9. Long, Y., \& Aleven, V. (2017). Enhancing Learning Outcomes Through Self-Regulated Learning Support with An Open Learner Model. User Modeling and User-Adapted Interaction, 27(1), 55-88. https://doi.org/10.1007/s11257-016-9186-6

10. Mattern, J., \& Bauer, J. (2014). Does teachers' cognitive self-regulation increase their occupational well-being? The structure and role of self-regulation in the teaching context. Teaching and Teacher Education, 43, 58-68. https://doi.org/10.1016/j.tate.2014.05.004

11. Miles, M. B., \& Huberman, A. M. (1992). Analisis data kualitatif: buku sumber tentang metode-metode baru. Jakarta: UI-Press.

12. Muhammedi. (2016). Perubahan Kurikulum di Indonesia: Studi Kritis tentang Upaya Menemukan Kurikulum Pendidikan Islam yang Ideal. Jurnal Raudhah, 4(1), 49-70. https://doi.org/10.30829/raudhah.v4i1.61

13. Raharjo, S. B. (2013). Evaluasi Trend Kualitas Pendidikan di Indonesia. Jurnal Penelitian Dan Evaluasi Pendidikan, 16(2), 511-532. https://doi.org/10.21831/pep.v16i2.1129

14. Santrock, J. W. (2007). Psikologi Pendidikan. Prenada Media Group. Jakarta: Prenada 
Media Group.

15. Schunk, D. H., \& DiBenedetto, M. K. (2020). Motivation and social cognitive theory. Contemporary Educational Psychology, 60, 1-10. https://doi.org/10.1016/j.cedpsych.2019.101832

16. Sugiyono. (2014). Metode Penelitian Kuantitatif, Kualitatif, dan RnD. Bandung: Alfabeta.

17. Sulisworo, D., Fitrianawati, M., Maryani, I., Hidayat, S., Agusta, E., \& Saputri, W. (2020). Students' self-regulated learning (SRL) profile dataset measured during Covid-19 mitigation in Yogyakarta, Indonesia. Data in Brief, 33. https://doi.org/10.1016/j.dib.2020.106422

18. Tosi, H. L., Locke, E. A., \& Latham, G. P. (1991). A Theory of Goal Setting and Task Performance. The Academy of Management Review, 16(2), 480. https://doi.org/10.2307/258875

19. Valle, A., Núñez, J. C., Ramón G. Cabanach, Julio Antonio González-Pienda, Susana Rodríguez, Pedro Rosário, ... María A. Muñoz-Cadavid. (2008). Self-regulated profiles and academic achievement. Psicothema, 20(4), 724-731.

20. Wang, H. H., Chen, H. T., Lin, H. S., \& Hong, Z. R. (2017). The effects of college students' positive thinking, learning motivation and self-regulation through a self-reflection intervention in Taiwan. Higher Education Research and Development, 36(1), 201-216. https://doi.org/10.1080/07294360.2016.1176999

21. Wilson, K., \& Narayan, A. (2016). Relationships Among Individual Task Self-Efficacy, Self-Regulated Learning Strategy Use and Academic Performance in A ComputerSupported Collaborative Learning Environment. Educational Psychology, 36(2), 236253. https://doi.org/10.1080/01443410.2014.926312

22. Wolters, C. A., \& Hussain, M. (2015). Investigating Grit and Its Relations with College Students' Self-Regulated Learning and Academic Achievement. Metacognition and Learning, 10(3), 293-311. https://doi.org/10.1007/s11409-014-9128-9

23. Wong, J., Baars, M., Davis, D., Van Der Zee, T., Houben, G.-J., \& Paas, F. (2019). Supporting Self-Regulated Learning in Online Learning Environments and MOOCs: A Systematic Review. International Journal of Human-Computer Interaction, 35(4-5), 356-373. https://doi.org/10.1080/10447318.2018.1543084

24. Zimmerman, B. J. (1989). A Social Cognitive View of Self-Regulated Academic Learning. Journal of Educational Psychology, 81(3), 329-339. https://doi.org/10.1037/0022-0663.81.3.329

25. Zimmerman, B. J. (2002). Becoming a Self-Regulated Learner: An Overview. Theory into Practice, Vol. 41, pp. 64-70. https://doi.org/10.1207/s15430421tip4102_2

26. Zimmerman, B. J., \& Martinez-Pons, M. (1990). Student Differences in Self-Regulated Learning: Relating Grade, Sex, and Giftedness to Self-Efficacy and Strategy Use. Journal of Educational Psychology, 82(1), 51-59. https://doi.org/10.1037/0022-0663.82.1.51

27. Zumbrunn, S., Tadlock, J., \& Roberts, E. D. (2011). Encouraging Self-Regulated Learning in the Classroom: A Review of the Literature Sharon. In Metropolitan Educational Research Consortium (MERC).

\section{PROFIL SINGKAT}

Rivan Gestiardi adalah Mahasiswa Program Studi Pendidikan Guru Sekolah Dasar. Fakultas Keguruan dan Ilmu Pendidikan. Universitas Ahmad Dahlan Yogyakarta.

Ika Maryani adalah Dosen Bidang IPA di Program Studi Pendidikan Guru Universitas Ahmad Dahlan. Latar Belakang Pendidikan dari S1 Pendidikan Kimia UNS dan S2 Pendidikan Sains UNS. Saat ini sedang aktif melakukan penelitian terkait pembelajaran IPA di Sekolah Dasnar dan faktor penentu keberhasilannya. Karya-karyanya telah dipublikasi dalam jurnal maupun seminar di tingkat nasional dan internasional. 